\title{
Um enfoque etnobiológico na formação do professor de ciências sensível à diversidade cultural: estudo de caso
}

\author{
An ethnobiological approach to science teacher education \\ that is sensitive to cultural diversity: a case study
}

Geilsa Costa Santos Baptista ${ }^{1}$

\begin{abstract}
Resumo: São apresentados resultados de uma pesquisa que teve por objetivo identificar como a etnobiologia - ciência que estuda as inúmeras relações entre os seres humanos e a natureza ao seu redor - pode contribuir para a formação do professor de ciências que seja sensível à diversidade cultural. Foram realizadas entrevistas semiestruturadas com nove professoras de Biologia que atuam nos níveis Fundamental e Médio da rede pública de ensino do estado da Bahia, antes e após as suas participações num curso de formação continuada tratando a etnobiologia e suas contribuições para o ensino de ciências. As análises aconteceram com base na comparação das respostas e revelaram indícios de mudanças das concepções após o curso. Conclui-se que a etnobiologia pode contribuir para a formação dos professores de ciências na medida em que o curso envolvendo esta ciência gerou oportunidades para que as professoras refletissem sobre as suas práticas pedagógicas, podendo ressignificá-las com relação à diversidade cultural.
\end{abstract}

Palavras-chave: Etnobiologia. Formação de professores. Ensino de Ciências. Diálogo intercultural.

\begin{abstract}
We present results of a survey that aimed to identify how ethnobiology - science that studies the many relationships between human beings and the natural world - can contribute to the formation of science teacher who is sensitive to cultural diversity. Semi-structured interviews were conducted with nine Biology teachers from public schools in State of Bahia, before and after their participation in a continuing training course addressing ethnobiology and its contribution to science education. The analyses were based on the comparison of the responses, and revealed some changes in conceptions of the teachers after the course. We concluded that ethnobiology could contribute to the formation of science teachers in the way that the course involving this science has generated opportunities for teachers to reflect on their teaching practices being able to offer them new understandings with respect to cultural diversity.
\end{abstract}

Keywords: Ethnobiology. Teachers' training. Science education. Intercutural dialogue.

\footnotetext{
${ }^{1}$ Programa de Pós-Graduação em Ensino, Filosofia e História da Ciência (UEFS-UFBA), Departamento de Educação, Universidade Estadual de Feira de Santana (UEFS), Km 03, Rodovia BR 116, S/N, Campus Universitário, CEP 44031-460, Feira de Santana, BA, Brasil. E-mail: <geilsabaptista@gmail.com>
} 


\section{Introdução}

Para Feldmann (2009), as práticas pedagógicas nas escolas são influenciadas pelas concepções dos professores, que, por sua vez, são resultantes das suas formações, sejam inicial e/ou continuada. Segundo Rodrigues, Krüger e Soares (2010), a concepção mais comumente interiorizada pelos professores de ciências é a do professor como transmissor de conhecimentos científicos inquestionáveis, e do estudante como mero receptor desses conhecimentos. Essa concepção torna muito difícil o reconhecimento da diversidade cultural presente nas salas de aula. Por conta disso é que o ensino de ciências no Brasil não vem, ao longo dos anos, estimulando o diálogo com outras formas de conhecer o mundo (LOPES, 1999), preservando a ideia de que a ciência ocidental constitui a única e legítima fonte de conhecimentos válidos.

De acordo com Candau (2011), a educação escolar que pretenda ser significativa para os estudantes necessita estar imbuída de práticas educativas sensíveis às diferenças culturais que emergem com cada vez maior força e visibilidade no cotidiano das escolas. No ensino de ciências, essa sensibilidade implica práticas pedagógicas comprometidas com a promoção do diálogo intercultural, ou seja, entre a cultura da ciência e as culturas dos estudantes. Nesse momento, concordando com Mortimer (2000), deve ocorrer uma relação simétrica de apresentação dos distintos significados atribuídos pelos interlocutores a um determinado tema que é objeto de estudo. O diálogo nas aulas de ciências gera oportunidades para a exposição das diferentes ideias, que serão consideradas e exploradas, cada qual segundo o seu contexto de origem e validade.

Contudo, para que o diálogo aconteça, é preciso que os professores investiguem e compreendam quais são os conhecimentos culturais que os estudantes trazem consigo para as salas de aula (BAPTISTA, 2007). Neste sentido, um estudo realizado por Baptista em 2007, numa escola pública do estado da Bahia, que atende estudantes agricultores e não agricultores revela que a etnobiologia permite, aos professores de ciências, investigarem - seja por meio da utilização dos seus procedimentos metodológicos e/ou das suas publicações - quais são os conhecimentos sobre a natureza que os estudantes possuem, e construírem estratégias de educação científica nas quais esses saberes sejam incluídos e considerados num diálogo cultural com a ciência (BAPTISTA, 2007). A etnobiologia é o estudo das complexas relações que existem entre seres vivos e sistemas culturais, tanto nas sociedades passadas quanto nas atuais (INTERNATIONAL SOCIETY OF ETHNOBIOLOGY, 2012).

Baptista (2007) adverte que o diálogo só será possível se houver uma sensibilização, por parte dos professores, quanto à diversidade cultural presente nas salas de aula, que permita compreender os espaços sociais dos estudantes e as suas concepções de origem, o que, por sua vez, torna necessária a formação docente inicial e continuada. No presente artigo, são apresentados e discutidos os resultados da tese de doutorado da autora, que teve por objetivo geral identificar como a etnobiologia pode contribuir para a formação de professores de ciências que seja sensível à diversidade cultural. Espera-se que os resultados aqui apresentados possam servir de base para as pesquisas sobre a formação de professores de ciências para a diversidade cultural, em particular, sobre o papel que a etnobiologia pode desempenhar nesse processo. 


\section{Metodologia}

O estudo foi de natureza qualitativa e aconteceu em 2009. A obtenção dos dados se deu por meio de entrevistas semiestruturadas realizadas com nove professoras de biologia, com idades entre 28 e 41 anos, antes e após a concretização de um curso de formação continuada para professores de ciências do Nível Básico da rede pública de ensino do estado da Bahia. As professoras assinaram um Termo de Consentimento Livre e Esclarecido, conforme Resolução vigente em 2009, de número 196/96, do Ministério da Saúde (BRASIL, 2003).

Sobre o número de participantes no curso, cabe informar que, das 15 vagas oferecidas, 14 foram preenchidas no momento da inscrição. Nove professoras realizaram as entrevistas antes do curso, e seis após o curso. Isso ocorreu devido às desistências de algumas das professoras inscritas que, segundo elas mesmas, não foram liberadas pelas direções das suas escolas para participação no curso.

O curso, com carga horária total de 132 horas, teve abordagem teórica ${ }^{2}$ e prática ${ }^{3}$ de forma interligada, sendo realizado na Universidade Estadual de Feira de Santana (UEFS). O objetivo foi contribuir para a sensibilização de professores quanto à diversidade cultural presente nas salas de aula.

As entrevistas foram registradas com auxílio de um gravador e transcritas para posterior análise. As seguintes questões guiaram as entrevistas: (1) O que é conhecimento tradicional ${ }^{4}$ para você? (2) Você investiga quais conhecimentos tradicionais os estudantes trazem consigo para as salas de aula? (3) Caso investigue, qual a metodologia adotada? (4) A sua prática de ensino aborda os saberes tradicionais dos estudantes? (5) Para você, o que é diálogo entre saberes? (6) Como você percebe a investigação dos saberes culturais dos estudantes? (7) Você conhece a etnobiologia e sua metodologia de pesquisa? (8) O que é ciência: Evolucionismo x Desenho Inteligente? E Astrologia x Astronomia? (9) E Ciências Biológicas, o que significa? Para cada entrevistada, foram criados códigos com o objetivo de garantir a sua privacidade, a saber: PE1 (Professora Entrevistada 1); PE2 (Professora Entrevistada 2) e, assim, sucessivamente.

\footnotetext{
${ }^{2}$ Os seguintes temas, entre outros, foram centrais para o desenvolvimento teórico do curso: - A etnobiologia, conceitos, seu objeto de estudo, procedimentos metodológicos de pesquisa e contribuições para o ensino de ciências; - A relevância da investigação da prática pedagógica e dos saberes culturais dos estudantes para o diálogo cultural no ensino de ciências.

${ }^{3}$ As estratégias para o desenvolvimento prático do curso foram: - Análises de textos relacionados com a temática; - Realização de procedimentos de pesquisa da etnobiologia para investigação dos saberes tradicionais dos estudantes das escolas onde atuam as professoras; - Produção de materiais didáticos e estratégias de ensino contendo os conhecimentos tradicionais dos estudantes e relações de semelhanças e de diferenças com o conhecimento científico biológico; - Intervenções no ensino de biologia nas escolas onde atuam as professoras baseadas no diálogo cultural.

${ }^{4} \mathrm{~A}$ pesquisa envolveu os conhecimentos tradicionais por serem prévios à aprendizagem escolar e por constituírem um dos possíveis modos de conhecer que se fazem presentes nas salas de aula de ciências. Os conhecimentos tradicionais são provenientes das comunidades tradicionais (por exemplo: agricultores, pescadores, ribeirinhos, quilombolas, entre outros), e são definidos por Berkes e Folke (1998) como um corpo cumulativo de conhecimentos, práticas e crenças resultantes do contato humano com o meio ambiente ao seu redor, tendo a cultura como mediadora desse processo.
} 
De posse das transcrições, foram elaboradas categorias de acordo com as respostas dadas pelas professoras. Dentro de cada categoria, as respostas foram organizadas, lado a lado, em um quadro, por antes e após o curso de formação continuada. As análises aconteceram sobre cada categoria, com base na comparação das respostas dadas pelas professoras antes e após o curso, e discutidas com base na literatura em educação, ensino de ciências e etnobiologia. O objetivo foi identificar a ocorrência, ou não, de mudanças das concepções por parte das professoras após as suas experiências de formação no curso.

\section{Resultados e discussão}

As entrevistas duraram entre trinta e sessenta minutos. O tempo médio foi de trinta minutos e 17 segundos para as entrevistas realizadas antes do curso, e de 24 minutos e quarenta segundos para as entrevistas realizadas após o curso.

Foram 14 as categorias contendo as respostas emitidas pelas professoras, a saber: (1) Significado de conhecimento tradicional; (2) Conceito de cultura e exemplos; (3) Relações dos conhecimentos tradicionais com os populares e de senso comum; (4) Como ocorre a construção dos conhecimentos; (5) Se ocorrem investigações dos conhecimentos tradicionais dos estudantes; (6) Metodologia utilizada para investigação dos conhecimentos tradicionais dos estudantes; (7) A importância da investigação dos conhecimentos tradicionais dos estudantes para o ensino; (8) A utilização dos conhecimentos tradicionais para introdução, compreensão e apreensão do conhecimento científico; (9) Conceito de diálogo entre saberes; (10) Conceito da etnobiologia e metodologia de pesquisa; (11) Conceito de ciência; (12) Conceito de biologia, de ensino de biologia; (13) Possibilidades de mudanças nas práticas pedagógicas após a participação no curso; (14) Críticas e sugestões sobre o curso. Por conta do curto espaço deste artigo, serão apresentadas apenas quatro dessas categorias $(7,9,10,11)$, cada uma contendo quadros (quadros 1, 2, 3 e 4, respectivamente à sequência das categorias) nos quais trechos das falas das professoras estão organizados lado a lado, por antes e após o curso de formação continuada.

\section{Categoria 7. A importância da investigação dos conhecimentos tradicionais dos estudantes para o ensino}

Antes do curso, as respostas dadas pelas professoras sobre qual seria a importância de investigar os saberes tradicionais dos estudantes revelaram motivos interligados. Para PE1, a investigação dos conhecimentos tradicionais permite acrescentar informações científicas aos conhecimentos prévios. De fato, a investigação dos conhecimentos tradicionais pode contribuir para a aprendizagem científica, porque é possível estabelecer relações entre aqueles conhecimentos e o conhecimento científico escolar (COBERN, 2004), em termos de suas semelhanças e de suas diferenças, o que poderá colaborar para que os estudantes ampliem os seus conhecimentos com conhecimentos científicos (BAPTISTA; EL-HANI, 2009).

$\mathrm{Na}$ resposta dada por PE6, é possível notar que, para ela, o ato de investigar está atrelado à ação. Isto é, a investigação dos saberes tradicionais dos estudantes está diretamente ligada à utilização desses conhecimentos nas salas de aula. Tal percepção é importante para o ensino e a formação de professores de ciências para lidarem com a diversidade cultural, se considerada 
Quadro 1. Exemplos das respostas das professoras sobre a importância da investigação dos conhecimentos tradicionais dos estudantes

\begin{tabular}{|c|c|}
\hline Antes do curso & Após o curso \\
\hline $\begin{array}{l}{[. . .] \text { uma forma de adquirir informação sobre }} \\
\text { aquilo e acrescentar com aquele conhecimento } \\
\text { cientifico... estar acrescentando na cultura deles } \\
\text { algo do conhecimento específico, específico da } \\
\text { escola... (PE1) }\end{array}$ & $\begin{array}{l}\text { [...] é importante... o que eles têm de vivência mesmo do cotidiano... } \\
\text { quando a gente procura saber sobre a energia e eles falam da } \\
\text { energia... eu sempre to buscando esses conbecimentos deles... porque } \\
\text { torna as aulas pra eles muito mais interessante. (PE6) }\end{array}$ \\
\hline $\begin{array}{l}{[. . .] \text { sempre digo pros meus alunos que os }} \\
\text { assuntos que eles estão vendo... que eles vão } \\
\text { usar... eu procuro mostrar pra eles que o que } \\
\text { eu to ensinando... que eles entendam o porque } \\
\text { que eles precisam aprender aquilo... (PE6) }\end{array}$ & $\begin{array}{l}\text { [...] não é fácil... dentro da perspectiva atual do ensino, onde a gente } \\
\text { tem um componente curricular... estrutura de aulas organizadas pra } \\
\text { dar conta da demanda da carga horária, dar conta disso dai é um } \\
\text { requisito a mais, por tentar fazer um paralelo pra o que o professor } \\
\text { já tem que fazer... a própria estrutura escola... O professor numa } \\
\text { escola pública... ele ainda não está na autonomia plena de buscar } \\
\text { esses conhecimentos, investigar... Muitos empecilhos, um deles... a } \\
\text { situação do professor enquanto quantidade de alunos... de turmas, } \\
\text { de horas aula, de tempo... não é impossivel, é difícil, e deve ser } \\
\text { inclusive adaptada e aos poucos inserida. Tem de entender que a } \\
\text { mudança não é de uma hora pra outra... (PE8) }\end{array}$ \\
\hline
\end{tabular}

Fonte: elaborado pela autora.

a perspectiva do professor investigador. Como discutem Rodrigues e Carvalho (2002), as investigações desenvolvidas pelos professores contribuem para o desenvolvimento dos processos de ensino, nos seus mais variados aspectos metodológicos. A investigação dos saberes tradicionais dos estudantes poderá contribuir para que os professores consigam estabelecer o diálogo com a cultura desses sujeitos, encorajando-os à participação. Consequentemente, e de forma atrelada, também poderá contribuir para a formação do professor, como momentos de produção do conhecimento pedagógico.

Após o curso, as respostas dadas pelas professoras foram semelhantes às respostas apresentadas antes do curso. Elas argumentaram que é importante ter em conta os conhecimentos culturais dos estudantes para a facilitação da aprendizagem, especialmente conhecimentos que tenham relações com os conteúdos de ensino, a exemplo da fala de PE6.

Apesar de todas as professoras admitirem como importante a investigação e a consideração dos conhecimentos tradicionais dos estudantes, uma delas, PE8, apontou alguns obstáculos para que isso venha a ocorrer. Ela argumentou que a estrutura curricular, a disponibilidade de tempo, o número de estudantes por classe, os encargos do professor, a sua falta de autonomia impedem que mudanças ocorram nas prráticas pedagógicas nesse sentido. A fala de PE8 traz argumentos interessantes sobre problemas que são comuns no meio social dos professores dentro das escolas, particularmente das públicas, sobre as quais recaiu o foco deste trabalho. Não há dúvida de que as condições de trabalho dos professores interferem nos seus saberes e práticas pedagógicas (TARDIF, 2002), muitas vezes dificultando mudanças, a exemplo da inclu- 
Quadro 2. Exemplos das respostas das professoras sobre diálogo entre saberes

\begin{tabular}{|c|c|}
\hline Antes do curso & Após o curso \\
\hline $\begin{array}{l}\text { [...] o encontro do meu conbecimento com o... } \\
\text { conhecimento do aluno... São trocas, trocas com certeza... } \\
\text { pode acontecer, justamente, ah, é uma superstição é, } \\
\text { agora, e eu sei o que é o cientifico, vamos dizer assim, o } \\
\text { que é realmente, o que acontece... a gente vai perguntar } \\
\text { por que isso é assim, a gente joga, ah, porque estou } \\
\text { menstruada, se eu tomar banho, isso me prejudica? E } \\
\text { isso eu sei que realmente é uma questão de crença, de } \\
\text { cultura, vamos dizer assim, aí vamos tentar explicar a ele } \\
\text { que não existe isso... (PE2) }\end{array}$ & $\begin{array}{l}\text { Turmas menores são bem mais fáceis de a gente ta } \\
\text { trabalhando o diálogo. Turmas grandes são impossiveis... } \\
\text { Primeiro a carga horária curta pra você tratar um } \\
\text { número de alunos enorme... se você tem cinquenta } \\
\text { alunos, uma aula tem cinquenta minutos, um minuto } \\
\text { pra cada aluno, não tem como você transformar um } \\
\text { diálogo com um aluno em um minuto... não tem como } \\
\text { você problematizar... Que a escola vai ta fazendo com } \\
\text { ele veja a importância daquilo que ele já traz e consiga } \\
\text { dialogar entre a ciência e o que ele tem como cotidiano... } \\
\text { vai depender dos contextos específicos... daquilo que } \\
\text { ele vai precisar usar no seu cotidiano... Depende da } \\
\text { atividade que ele pratica... da atividade que ele tem no } \\
\text { seu contexto social. (PE1) }\end{array}$ \\
\hline $\begin{array}{l}{[. . .] \text { o diálogo na sala de aula às vezes ele acaba sendo... }} \\
\text { barreira ... Quando a gente pergunta, eles aprisionam } \\
\text { questões que eles gostaria de colocar... o trabalho } \\
\text { com a questão de respeito, a maneira do pensamento } \\
\text { estruturado pra cada conteúdo, e eu acho que isso é muito } \\
\text { importante... como é que ele ta pensando do assunto... } \\
\text { Quando eu comecei a dar aula... eu tinha certęa que } \\
\text { ensinar era dominar informação... Eu ressignificar, } \\
\text { desestimular essa minha maneira de pensar na medida } \\
\text { em que eu me preparava pra dar aula e ia me expor e } \\
\text { não conseguia atingir o meu limite... Quando eu pedia a } \\
\text { resposta, com a própria resposta da avaliação de nota... } \\
\text { e ai foi que eu percebi que a aprendizagem nunca ia } \\
\text { acontecer... de mim pra ele, de me expondo apenas... eu } \\
\text { acredito que essa questão do conhecimento tradicional, } \\
\text { no caso de agricultores se revelarem mesmo... a própria } \\
\text { vergonha de tratar de informaçôes e de ser motivo de } \\
\text { brincadeiras... o aluno ele ainda entende que o professor } \\
\text { domina, é detentor de toda a informação.. do saber e tem } \\
\text { de ser... (PE8) }\end{array}$ & $\begin{array}{l}{[. . .] \text { eu achei muito interessante o diálogo de saberes }} \\
\text { porque até então a minha prática não abordava, era só } \\
\text { da exposição. Eu dava um conteúdo e eles ficavam a } \\
\text { mercê das minhas ideias.... eu abri a minha visão com } \\
\text { relação ao diálogo... porque ele leva você, leva o aluno a } \\
\text { enxergar... Que não é só o conhecimento do professor... } \\
\text { através do diálogo a gente vai ter um enriquecimento } \\
\text { mútuo... (PE3) }\end{array}$ \\
\hline
\end{tabular}

são de investigação e consideração dos conhecimentos tradicionais dos estudantes. Contudo, é importante tanto reconhecer esses problemas quanto partir para reflexões críticas sobre essas condições de trabalho, de modo a gerar, dentro dos limites, ações que possam transformá-las ou, ao menos, ressignificá-las.

Nesse sentido, é possível observar na transcrição da sua fala, que PE8 pareceu considerar, também, a busca de soluções para os problemas por ela identificados, assumindo uma 
Quadro 2. continuação

\begin{tabular}{|c|c|}
\hline Antes do curso & Após o curso \\
\hline $\begin{array}{l}\text { [...] durante a minha formação acadêmica não pensava } \\
\text { em hoje ser uma educadora, porém o diálogo entre saberes } \\
\text { deve estar mais presente e consolidado em sala de aula, } \\
\text { sei que posso valorizar ainda mais o conbecimento } \\
\text { que meus alunos detêm e posso ajudá-los a serem } \\
\text { investigadores até das suas verdades, fazendo-os, mesmo } \\
\text { que difícil e para alguns colegas, impossivel... posso fazer } \\
\text { a diferença como um beija-flor na queimada de um trecho } \\
\text { da floresta... (PE9) }\end{array}$ & $\begin{array}{l}\text { [...] na verdade o conhecimento cientifico ele vem... somar } \\
\text { aos conhecimentos tradicionais... Por exemplo: indios } \\
\text { que morrem de malária, eles não tem conbecimento, } \\
\text { eles não se protegem, né, do transmissor. Porque ele } \\
\text { não tem conhecimento que aquela doença exista, ou ele } \\
\text { tem o conhecimento dele... sabe que pode usar, sei lá, } \\
\text { uma reza, um chá de uma erva... mas ele não tem a } \\
\text { ideia, a sequência de como o processo se dá... a ciência } \\
\text { vem a contribuir para a solução de problemas. É } \\
\text { um dos grandes problemas quando são introduzidos } \\
\text { conhecimentos cientificos é a aplicabilidade. O } \\
\text { importante é levar os alunos a ver essa aplicabilidade, } \\
\text { né? (PE5). }\end{array}$ \\
\hline & $\begin{array}{l}\text { Tem uma parte que é colocado como conteúdo pra } \\
\text { gente trabalhar... como trabalhar isso em sala de aula } \\
\text { eu fico sem saber como, porque a gente foi preparada } \\
\text { cientificamente. Por exemplo... é muito importante a } \\
\text { questão das plantas medicinais. Porque muitas vezes } \\
\text { eles utilizam e tem dois caminhos: um que é o científico, } \\
\text { né, que foi levado pra pesquisa na academia.. que é só } \\
\text { especifico pra determinadas coisas, mas que eles utilizam } \\
\text { pra outros tipos de doenças que eles desenvolvem... E } \\
\text { até eles mesmo, que têm o conhecimento em casa, têm } \\
\text { o remédio, acha que o que vai funcionar é o que tá na } \\
\text { farmácia... quando a gente pensa que o rural tá tão, } \\
\text { querem copiar o pessoal da zona urbana... os mais } \\
\text { jovens, eles não querem seguir os ensinamentos dos seus } \\
\text { pais, avós. Principalmente os que vão pra escola. (PE9) }\end{array}$ \\
\hline
\end{tabular}

Fonte: elaborado pela autora.

posição esperançosa em relação à possibilidade de mudanças na prática pedagógica, no que tange ao diálogo com os conhecimentos dos estudantes, o que é importante como requisito para que as ideias aprendidas durante o curso possam dar vez a ações.

\section{Categoria 9. Conceito de diálogo entre saberes}

Algumas professoras conceituaram o diálogo entre saberes culturais como encontro de conhecimentos, e troca de informações para construção de conhecimentos científicos. Serve como exemplo a fala de PE2. Essa professora utilizou o termo "troca" nas suas falas. Quando foi questionada sobre o significado desse termo, a sua resposta foi numa direção pouco ade- 
Quadro 3. Exemplos das respostas das professoras sobre o conceito da etnobiologia e metodologia de pesquisa

\begin{tabular}{|c|c|}
\hline Antes do curso & Após o curso \\
\hline $\begin{array}{l}{[. . .] \text { estaria relacionada justamente a trazer... esses }} \\
\text { conhecimentos, das formas de cultura... Não conheço a } \\
\text { fundo, mas deve ser entrevistas, observações ao fundo... } \\
\text { (PE1) }\end{array}$ & $\begin{array}{l}{[. . .] \text { seria a própria visitação dessas comunidades dos }} \\
\text { alunos, procurando saber como eles se relacionam com } \\
\text { a natureza... Observaçôes... Anotações nos diários de } \\
\text { campo... (PE1) }\end{array}$ \\
\hline $\begin{array}{l}\text { [...] busca na ciência explicação pra aquilo, se existe } \\
\text { uma, uma explicação científica... (PE2) }\end{array}$ & $\begin{array}{l}{[. . .] \text { ela é uma disciplina... que reúne a biologia e a }} \\
\text { antropologia pra estudar como as sociedades tradicionais } \\
\text { se relacionam com o mundo natural ao seu redor.. essas } \\
\text { interaçoes dos seres vivos e os sistemas culturais... (PE3) }\end{array}$ \\
\hline $\begin{array}{l}{[. . .] \text { é o estudo da relação entre a natureza, adaptação do }} \\
\text { homem e suas crenças... Como ela pesquisa? Eu não sei } \\
\text { te informar. (PE3) }\end{array}$ & $\begin{array}{l}\text { Através da pesquisa de campo... entrevistas, e outras } \\
\text { técnicas... estudar os seus conbecimentos lá, na cultura } \\
\text { deles... O que eles trouxeram para a sala o professor } \\
\text { pode investigar na comunidade deles. (PE5) }\end{array}$ \\
\hline $\begin{array}{l}\text { [...] seria o estudo das relações biológicas... o ser bumano } \\
\text { no contexto social, o que ele tem de conbecimento... dentro } \\
\text { do local que ele vive, relacionado a questão da ciência... } \\
\text { Entrevistas com a comunidade e observar a área... } \\
\text { (PE4) }\end{array}$ & $\begin{array}{l}\text { Agora, eu posso falar um pouquinho... ela estuda um } \\
\text { grupo social, um grupo social mais a sua relação com } \\
\text { a natureza, com o meio que o cerca... dentro de uma } \\
\text { abordagem histórica, social e cultural... (PE6). }\end{array}$ \\
\hline $\begin{array}{l}\text { [...] en tive como disciplina na UEFS e fizemos uma } \\
\text { pesquisa... a preocupação era buscar esse conhecimento } \\
\text { fora do científico... (PE5) }\end{array}$ & \\
\hline $\begin{array}{l}\text { A gente escuta falar... mas definição nunca peguei pra } \\
\text { ler isso é etnobiologia. Etnobiologia... Etno vem de que } \\
\text { palavra? (PE6) }\end{array}$ & \\
\hline
\end{tabular}

Fonte: elaborado pela autora.

quada para uma definição de diálogo encontrada na literatura em educação científica utilizada no presente trabalho. Sobre essa fala é possível perceber que o termo "troca" trataria de uma substituição de concepções prévias dos estudantes por conhecimentos científicos escolares, por serem estes últimos mais corretos, superiores aos demais conhecimentos.

Uma das professoras entrevistadas, PE8, afirmou que enfrenta barreiras para a realização do diálogo, tanto por parte dos estudantes quanto da sua pessoa, enquanto professora. No caso dos estudantes, ela argumentou que isso acontece porque eles sentem dificuldades de expor os seus conhecimentos nas salas de aula. Já no caso dela, PE8 apresentou, como justificativa, a sua formação inicial, que a preparou dentro da visão de que ensinar significa apenas 
Quadro 4. Exemplos das respostas das professoras sobre o conceito de ciência

\begin{tabular}{|c|c|}
\hline Antes do curso & Após o curso \\
\hline $\begin{array}{l}{[. . .] \text { a ciência é uma parte da nossa cultura que }} \\
\text { tenta explicar os fenômenos... na natureza, que tenta } \\
\text { investigar, solução para os problemas que nós temos } \\
\text { e tenta conhecer mesmo o ambiente onde a gente } \\
\text { vive... (PE1) }\end{array}$ & $\begin{array}{l}\text { [...] definir ainda é muito difícil pra mim... Existe a ciência } \\
\text { ocidental, que é aquela coisa que veio do colonialismo, que } \\
\text { por sua vez. tem relação com o século XVII, das etapas, } \\
\text { do método... é o caminho que vai permitir o entendimento } \\
\text { do mundo natural... eu digo que não é, mas, às vezes eu } \\
\text { me pergunto: a medicina ela vem desenvolvendo estudos } \\
\text { que mostram como a fé de um paciente tem ajudado a ele } \\
\text { melhorar... a ciência não trabalha com o mundo sobrenatural, } \\
\text { mas quando eu vejo que certas coisas que não era do dominio } \\
\text { da ciência já sendo pesquisada, eu fico assim. (PE5) }\end{array}$ \\
\hline $\begin{array}{l}\text { [...] a ciência é um campo tão grande... é uma gama } \\
\text { de conhecimento inter-relacionados... Sei lá, me perdi } \\
\text { toda agora... Vixe, me apertou... É uma coisa tão } \\
\text { abstrata, pra dizer assim? (PE3) }\end{array}$ & $\begin{array}{l}\text { [...] é uma coisa assim ampla... não se tem um único } \\
\text { conceito... ela tem a ver com o natural... na realidade ela não } \\
\text { é imutável... pra ser cientifico um conceito tem de passar } \\
\text { por uma comunidade cientifica e defender, definir o que é } \\
\text { cientifico... ela tem características... que lhes são próprios } \\
\text { porque é uma cultura... o fato de não ter uma única definição, } \\
\text { é por causa dessa mutabilidade dela... (PE6) }\end{array}$ \\
\hline $\begin{array}{l}\text { É o conbecimento acerca de alguma coisa. Qualquer } \\
\text { estudo criado, relacionado, em relação a algo... } \\
\text { ciência é conbecimento... o científico é tudo aquilo } \\
\text { que precisa ser investigado, foi pesquisado precisa ser } \\
\text { comprovado cientificamente, mas eu acredito que o } \\
\text { que eles trazem também é um, é uma ciência, é um } \\
\text { conhecimento popular, ou tradicional... Também é } \\
\text { ciência... (PE4) }\end{array}$ & $\begin{array}{l}\text { [...] cultura, com características, linguagem, forma de se } \\
\text { comunicar... como os outros grupos culturais também têm. } \\
\text { É o que faz ser validado dentro dela... Eu lembro que eu } \\
\text { insistia muito na questão do método, mas eu pude reler, faz̧er } \\
\text { releituras nesses últimos dias... eu posso definir a ciência como } \\
\text { uma das formas de explicaçoes da naturez̨a validada por um } \\
\text { grupo, que é o grupo cientifico. (PE8) }\end{array}$ \\
\hline $\begin{array}{l}{[. . .] \text { na forma de estudar existem várias ciências... }} \\
\text { Eu acho que é a questão... Da divulgação... E da } \\
\text { metodologia do estudo... O acadêmico, ele trabalha } \\
\text { em cima de passos... Não só a divulgação. Eu acho } \\
\text { que é essa coisa do método... (PE5) }\end{array}$ & $\begin{array}{l}\text { [...] organização de algumas descobertas em todos os campos, } \\
\text { de biológicas, de exatas... uma comunidade que produz saber e } \\
\text { esse saber é o saber cientifico... que estuda e que permite que } \\
\text { outros cientistas estudem a partir das suas descobertas... uma } \\
\text { coisa que não está pronta... pode descobrir novas descobertas } \\
\text { tendo sempre o dia a dia... (PE9) }\end{array}$ \\
\hline $\begin{array}{l}{[. . .] \text { taria vinculada... ao método, a uma }} \\
\text { observação, a uma experimentação e a um resultado } \\
\text { e a uma discussão desses resultados, inclusive a uma } \\
\text { passível, a uma... é... uma repetição disso daí... } \\
\text { (PE8) }\end{array}$ & \\
\hline
\end{tabular}

Fonte: elaborado pela autora. 
ter domínio de conhecimentos científicos a serem transmitidos. Na fala de PE8, também é possível notar que ela reconhece a necessidade de mudanças nesse sentido, considerando que esse reconhecimento surgiu da sua própria experiência de ensino, quando passou a preocuparse com a aprendizagem dos seus estudantes.

Essa relação apontada por PE8 está presente nas discussões da literatura específica sobre a formação de professores de ciências. Segundo Delizoicov (2004), por exemplo, a formação inicial do professor exerce influência sobre a sua atuação, tanto ao adotar práticas inovadoras quanto ao manter práticas tradicionais de ensino. Especificamente no caso do ensino de ciências e diversidade cultural, isso significa dizer que, a depender da sua formação dentro das universidades, o professor de ciências poderá desenvolver concepções que lhe permitam inovações e melhorias voltadas para o diálogo entre saberes culturais. Ou, contrariamente, a perpetuação de uma prática de ensino que objetiva a mera transmissão de conhecimentos científicos escolares, sem participções por parte dos estudantes.

Ainda de forma associada com a dificuldade de exposição dos conhecimentos por parte dos estudantes, PE8 também argumentou que existem discriminações nas salas de aula com relação aos estudantes provenientes das comunidades tradicionais agrícolas. Para ela, as discriminações acontecem porque os próprios estudantes se sentem envergonhados em apresentar seus conhecimentos, porque creem que apenas os professores são detentores de conhecimentos válidos. É possível que os estudantes dessa professora sintam dificuldades de exposição verbal dos seus conhecimentos culturais porque, como argumenta Certeau (1998), esses conhecimentos estão cravados em um saber-fazer não discursivo, em práticas cotidianas nem sempre verbalizadas/verbalizáveis. Daí, a importância da utilização dos procedimentos de pesquisa da etnobiologia para que seja possível elucidar, de alguma forma, os conhecimentos tradicionais dos estudantes. Currie (2006) argumenta que as discriminações nas salas de aula podem levar os estudantes a um sentimento de inferioridade, o que inibirá as suas participações nos processos de ensino e aprendizagem. Se os estudantes de PE8 que são agricultores se sentem envergonhados, é possível que as discriminações nas suas aulas sejam frequentes e que não assuma uma posição que contribua para combatê-las.

De acordo com Canen (2001), a reflexão sobre a prática pedagógica permite, ao professor, o reconhecimento dos problemas enfrentados nas suas salas de aula com relação à diversidade cultural e traz contribuições para que mudanças ocorram na prática pedagógica com relação ao respeito e à consideração dessa diversidade. Esta importância apontada pelo autor está presente na fala de PE9, podendo ser um indicativo de que podem ocorrer mudanças na sua realidade de ensino no tocante ao diálogo entre saberes culturais nas salas de aula de ciências.

Após o curso, foi interessante notar, nas falas de algumas professoras, a necessidade de explicarem como elas não utilizavam o diálogo, antes da realização do curso de formação continuada, como possibilidade de argumentação, enriquecimento e valorização dos conhecimentos tradicionais pelos próprios estudantes, como é possível constatar na fala de PE3. Essa necessidade de explicação significa que as professoras refletiram sobre como o diálogo pode contribuir para a facilitação do ensino que respeita e valoriza os conhecimentos culturais dos estudantes. Como consequência disso, é possível que elas possam mudar as suas didáticas, no sentido de considerar as diversas falas e argumentos nos momentos de ensino nas salas de aula. Como bem ressalta Schön (1992), o fato de os professores refletirem sobre as suas ações contribui para a construção de novos saberes e práticas pedagógicas. 
Após o curso, assim como nas entrevistas realizadas antes, algumas professoras também apontaram dificuldades para o estabelecimento de diálogos nas salas de aula. Essas dificuldades estiveram relacionadas à elevada quantidade de estudantes nesses espaços e ao tempo da hora-aula, que, segundo elas, é insuficiente para a exploração das falas, como é possível constatar na resposta de PE1. Segundo Jimenéz-Aleixandre, Bugallo Rodríguez e Duschl (2000), a argumentação é relevante para o ensino de ciências, porque desenvolve, nos estudantes, a capacidade para entenderem o que sabem e por qual motivo acreditam nos seus saberes, além de permitir-lhes avaliar os seus conhecimentos e os conhecimentos científicos no que diz respeito à sua eficácia e às suas limitações. No contexto do ensino de ciências, a construção de conhecimentos científicos é determinada pela negociação de significados entre os estudantes e os professores nos espaços sociais das salas de aula (MORTIMER, 2000). Daí entende-se que é necessária a problematização das falas dos sujeitos envolvidos no processo comunicativo que seja dentro de um espaço de tempo suficientemente prolongado, o que, obviamente, não será possível para o professor nas salas de aula cujo número de estudantes seja elevado. Será difícil, por exemplo, que o professor explore com tranquilidade as falas de cada um dos estudantes.

A problemática apontada por PE1, com relação ao tempo de que ela dispõe para a realização do diálogo, poderia ser minimizada com a diminuição do número de estudantes por turmas. Todavia, é preciso pensar nos meios para o alcance desta meta. Dentre eles, é possível citar a mobilização por parte dos professores de modo que se sintam corresponsáveis pela busca de melhores condições de trabalho, tanto físicas quanto sociais (ZARAGOZA, 1999).

Outra dificuldade apontada pelas professoras após o curso foi a desvalorização que muitos estudantes oriundos do campo demonstram ter dos seus conhecimentos tradicionais diante dos conhecimentos científicos, e a falta de uma formação docente apropriada para lidar com isto. Serve como exemplo a fala de PE9. Para Hill (2003), as enormes desigualdades em termos de recursos, sobretudo econômicos, têm levado muitos jovens à discriminação da própria pessoa e do meio sociocultural de onde vêm. Assim, é muito comum encontrar homens e mulheres do campo que se sentem inferiorizados diante de sociedades economicamente mais favorecidas, e, talvez como um mecanismo de defesa e aceitação, essas pessoas negam os seus saberes, preferindo, antes, os saberes dos mais favorecidos. A educação escolar pode contribuir fortemente para reverter essa situação, desde que não veja, nos estudantes, a possibilidade de capacitação técnica, mas, sim, de promoção intelectual, crítica e reflexiva (HILL, 2003).

A promoção do diálogo entre saberes culturais constitui excelente oportunidade para que os estudantes de PE9, e de outras realidades semelhantes, possam refletir sobre as suas origens, conhecimentos e razões. Do mesmo modo, sobre a importância da escola, do ensino de ciências como espaço de respeito à diversidade cultural, que contribui para a ampliação de conhecimentos e para as suas autonomias nas tomadas de decisões frente a situações nas quais necessitem realizar escolhas, não apenas nas salas de aula, mas, também, em outros contextos das suas vidas.

Um dos argumentos centrais do pluralismo epistemológico (COBERN; LOVING, 2001) é o de que os professores de ciências devem conduzir as suas aulas com a meta de que os estudantes consigam reconhecer a natureza da ciência que está sendo ensinada, bem como as possibilidades de aplicação dos seus produtos (conhecimentos científicos) nos contextos em que forem solicitados e/ou apropriados. Tal meta, é lógico, permite não apenas a demarcação da ciência com relação aos demais sistemas de saberes, mas, também, destes com relação à ciência. É possível que as professoras entrevistadas tenham se apropriado da ideia de que o 
ensino de ciências que tem por meta a compreensão dos conhecimentos científicos por meio de diálogo contribui para que os estudantes consigam demarcar os contextos de aplicação dos saberes culturais envolvidos, como pode ser percebido nas transcrições das falas de PE1 e PE5.

$\mathrm{Na}$ fala de PE1, é possível notar, de forma explícita, a sua concepção de que a aplicabilidade dos conhecimentos culturais por parte dos estudantes dependerá, exclusivamente, das suas necessidades em contextos e situações específicas. Já na fala de PE5, a concepção que se apresenta é a de que o ensino de ciências, especialmente para estudantes pertencentes às comunidades tradicionais, contribui para que os sujeitos utilizem os conhecimentos científicos com criticidade para solucionar problemas que aparecem dentro dos seus espaços sociais. Essas concepções estão de acordo com um dos pressupostos do construtivismo contextual: de que o ensino de ciências deve promover, nos estudantes, a compreensão da natureza da ciência e dos contextos de aplicação dos seus produtos, ou conhecimentos científicos (COBERN, 1996).

\section{Categoria 10. Conceito da etnobiologia e metodologia de pesquisa}

As respostas dadas pelas professoras sobre o conceito da etnobiologia foram classificadas em dois grupos: (1) professoras que já cursaram disciplinas de etnobiologia, e (2) professoras que não as haviam cursado. No presente estudo, foram consideradas professoras que já cursaram a etnobiologia aquelas que tiveram esta ciência como componente curricular nas suas graduações ou participaram de algum curso promovido por algum evento científico, contrariamente às professoras que nunca cursaram a etnobiologia.

As professoras que já haviam cursado a etnobiologia apresentaram respostas que convergem para os seguintes entendimentos: - A etnobiologia como o estudo dos saberes biológicos dentro de um contexto social (PE5); - A etnobiologia como estudo dos saberes biológicos de determinados grupos sociais e suas relações com a ciência, de modo a buscar a valorização desses saberes (PE4).

As respostas dadas pelas professoras que não cursaram a etnobiologia mostraram que esta ciência consiste num estudo que revela os conhecimentos das culturas e das suas relações com a natureza (PE1 e PE3). Uma das professoras, PE6, não apresentou uma explicação do significado do termo.

É consensual para a maioria dos etnobiólogos que este campo de investigação se dedica ao estudo, no sentido mais amplo possível, do conjunto complexo de relações de plantas e animais com as sociedades humanas passadas e presentes (BERLIN, 1992). Partindo desta definição, é possível a afirmativa de que as professoras que já cursaram a etnobiologia se aproximaram mais desta compreensão do que seja esta ciência do que aquelas que não as cursaram. Neste último caso, as respostas ou não apresentaram uma definição ou, então, não demonstraram clareza.

As professoras que já cursaram etnobiologia apresentaram, de qualquer modo, inadequações nas suas respostas. Serve, como exemplo, a concepção de PE2. Para ela, após investigar os saberes tradicionais, é preciso buscar, na ciência, uma validação para esse conhecimento. Isso não se mostra adequado porque os estudos etnobiológicos - ao se ocuparem das classificações, das interpretações e dos modos de manejo da natureza das comunidades tradicionais - buscam, sobretudo, um diálogo entre o conhecimento local/tradicional e o conhecimento científico acadêmico, com o intuito de contribuição mútua, e não de validação do primeiro por este último (ALBUQUERQUE; LUCENA, 2004). 
Após o curso, as respostas dadas pelas professoras foram mais ampliadas e convergiram para a explicação de que a etnobiologia é uma ciência que estuda as interações que são estabelecidas entre o ser humano, enquanto um ser cultural, e a natureza ao seu redor. Esta é uma explicação condizente com o significado proposto para a conjunção da etnobiologia com o ensino de ciências na escola, como meio para investigação e compreensão dos conhecimentos tradicionais dos estudantes relacionados com a natureza (BAPTISTA; EL-HANI, 2009). Servem, como exemplos, as falas de PE3 e PE6.

O fato de as professoras terem compreendido o conceito de etnobiologia que foi trabalhado durante o curso aumenta as chances de que possam utilizar esta ciência como subsídio para a investigação dos conhecimentos tradicionais dos estudantes, por propiciar o entendimento de como esses saberes são construídos culturalmente, das experiências dos indivíduos dentro dos seus entornos naturais e sociais.

Sobre os procedimentos metodológicos das pesquisas etnobiológicas, antes do curso, as professoras que nunca cursaram etnobiologia ou não souberam responder, por exemplo PE3, ou, então, apresentaram respostas inseguras, apontando a entrevista como técnica para coleta de dados, por exemplo PE1. As professoras que cursaram etnobiologia responderam, por sua vez, que esta ciência trabalha com a observação e entrevista, por exemplo PE4.

Após o curso, as respostas apresentadas pelas professoras foram relacionadas com as que forneceram antes do curso, porém, de forma mais alargada. Isso porque colocaram que não somente entrevistas, questionários e observações podem ser utilizadas na etnobiologia, mas, também, visitas às comunidades tradicionais, anotações em diários de campo e outras técnicas. Servem como exemplos as falas de PE1 e PE5. Isso pode ser um indicativo de que elas refletiram sobre a possibilidade de utilização da etnobiologia nas suas práticas pedagógicas. Do mesmo modo, que, ao aprenderem, durante o curso de formação continuada, sobre os principais procedimentos metodológicos da etnobiologia, elas tenham identificado quais as técnicas que julgaram aplicáveis a investigações dentro dos contextos específicos das suas realidades de ensino.

Cumpre informar que a etnobiologia não utiliza apenas as entrevistas, questionários e observações para coleta de dados. A etnobiologia constitui um campo interdisciplinar, com diferentes interfaces entre a biologia, a antropologia e a sociologia (ALBUQUERQUE; LUCENA, 2004) e, como tal, vale-se da variedade de técnicas utilizadas por estas disciplinas para a captação dos conhecimentos que determinados grupos culturais possuem sobre o mundo natural, como, por exemplo, a realização de filmagens e fotografias.

\section{Categoria 11. Conceito de ciência}

No que tange aos conceitos de ciência que sejam compatíveis com a perspectiva do diálogo intercultural, foram considerados como adequados aqueles que se aproximaram do conceito proposto por Cobern e Loving (2001). Para estes autores, apesar de não existir um conceito único para o que seja ciência, devido à complexidade que envolve o termo, é preciso reconhecer a necessidade de uma definição que seja prática para os propósitos de ensinar ciências na atualidade. De maneira geral, estes autores consideram que a ciência constitui um dos modos de conhecer que foram gerados nas sociedades ocidentais modernas, com valores e contextos de aplicação que são particulares, que diferem das outras formas de interpretar o mundo (COBERN; LOVING, 2001). 
Mesmo reconhecendo que uma definição única para o termo "ciência" é algo difícil de ser conseguido, Cobern e Loving (2001) sistematizam o que chamam de uma "Descrição Padrão de Ciência", baseada numa visão pragmática amplamente aceita pela comunidade científica e em certas áreas críticas de consenso sobre a natureza da ciência identificada na literatura sobre educação científica. Esta descrição inclui as seguintes características: (1) A ciência é um sistema explicativo naturalístico e materialista que busca explicar fenômenos naturais, devendo ser, idealmente, testável de maneira objetiva e empírica; (2) A ciência, como tipicamente concebida, é fundamentada em compromissos metafísicos sobre a maneira como o mundo "realmente é”. Entre esses compromissos, encontram-se os pressupostos de que o conhecimento sobre a natureza é possível; de que há ordem na natureza; de que existe causação na natureza; (3) Não obstante, é o consenso da comunidade científica que, em última instância, determina o que deve ser qualificado como ciência. Ainda que uma ideia agrupe todas as características citadas acima, ela só será considerada ciência se for assim julgada pela comunidade científica.

Segundo Irzik e Nola (2011), ensinar aos estudantes as características da ciência que são amplamente aceitas pela história, filosofia e sociologia da ciência e pela literatura em educação científica é importante, especialmente porque fornecem aspectos menos controversos sobre a natureza da ciência, porém, isso possui muitas deficiências e limitações. Irzik e Nola (2011) citam, por exemplo, a questão da metodologia da pesquisa científica. Segundo eles, embora seja correto o argumento de que não existe um método único para se fazer ciência, ele não pode ser considerado como menos controverso sobre a natureza da ciência, porque existem metodologias e regras metodológicas que orientam a prática científica de maneira geral. Como alternativa, Irzik e Nola (2011) propõem uma caracterização de ciência baseada na "semelhança de família". Segundo estes autores, é preciso a consideração de que existe um conjunto de características que são próprias de algumas ciências, mas não de outras, formando, assim, um conjunto de semelhança de família. Ou seja, existem diferenças entre as ciências, mas, também, semelhanças entre uma e outra (IRZIK; NOLA, 2011).

Antes do curso, algumas professoras apresentaram definições não condizentes com relação à definição de ciência de Cobern e Loving (2001). Já outras professoras, apresentaram explicações condizentes. Para PE1, a ciência constitui parte da cultura humana, tentando investigar os fenômenos com o propósito de conhecer o ambiente em que vivemos e, assim, solucionar os problemas da humanidade. Essa concepção traz um conceito bem próximo daquele defendido pela maioria dos pesquisadores na literatura em ensino de ciências, como, por exemplo, Lederman (2006), que caracteriza a ciência como uma em meio às várias culturas existentes que buscam descrever os fenômens naturais.

PE3 não conseguiu apresentar uma explicação compreensível do que seja ciência. Já PE4 apresenta explicação generalista sobre este termo. Para ela, a ciência é qualquer estudo ou conhecimento geral sobre algo. É importante considerar a carência de constituição histórico -epistemológica durante a formação da maioria dos professores de ciências. Para Delizoicov, Angotti e Pernambuco (2002), uma licenciatura fragmentada em disciplinas, que privilegia o aprendizado de conteúdos específicos, destituídos de qualquer discussão sobre a sua epistemologia e sobre o seu papel histórico, termina por levar os futuros professores à não-compreensão da natureza da ciência. Por conseguinte, a não-separação das fronteiras entre a ciência e os demais sistemas de saberes, como ficou evidente nas falas de PE4, que incluiu todas as formas de conhecimento como sendo ciência. 
Também é importante considerar sobre as respostas dadas por PE3 e PE4, que não apenas as suas formações podem ter influenciado nas suas falas para o significado do termo ciência, mas, também, a forma como a questão lhes foi apresentada: - Para você, o que é ciência: Evolucionismo x Desenho Inteligente? E Astrologia x Astronomia? É possível que as professoras não tenham compreendido bem essa questão interpretando-a como cobrança de apresentação de uma resposta pronta e acabada das suas partes para cada um destes termos. Assim, tenham sentido dificuldades para formular com clareza uma resposta para o significado do termo ciência.

$\mathrm{Na}$ resposta dada por PE4 para o que ela entende por ciência, também apareceu a concepção de que os conhecimentos tradicionais são produtos de um tipo de ciência, que difere daquela praticada pela comunidade científica. Essa concepção é inadequada, pois, concordando com El-Hani e Bandeira (2008), os conhecimentos tradicionais não são construções da ciência, mas, sim, construções legítimas das comunidades tradicionais e, portanto, válidos de acordo com critérios epistêmicos que são definidos em seus próprios padrões culturais. Do mesmo modo, é inadequada a concepção de que apenas o método e a divulgação permitem a diferenciação entre os conhecimentos tradicionais e o científico, como argumentou PE5. O que permite a diferenciação é todo o conjunto de características que são peculiares a cada uma dessas formas de conhecer (BANDEIRA, 2001).

Sobre a concepção de PE4 de que ciência é conhecimento, é importante destacar que, de fato, no sentido etimológico da palavra, o termo "ciência" significa conhecimento; contudo, a maneira como as práticas científicas se desenvolvem na atualidade não contribuem para a definição de ciência apenas como conhecimento, mas, sim, como uma das diversas formas de conhecimento, como um dos modos específicos de produção de conhecimentos (EL-HANI; BANDEIRA, 2008). De acordo com Cobern e Loving (2001), o entendimento de que todas as formas de conhecimento podem ser consideradas como ciência, de modo algum, contribui para a comunicação intercultural, mas, sim, para o não-reconhecimento das diferenças culturais presentes nas salas de aula, na medida em que em vez de reconhecer a diversidade de formas de conhecimento ali presentes, apenas as engloba todas como formas de ciência. Uma consequência disso é a de que os estudantes não conseguirão aplicar os diversos conhecimentos que têm ao seu dispor nos mais variados contextos e situações nos quais esses conhecimentos thes sejam solicitados. A demarcação entre a ciência e outras formas de conhecimento deve ser preservada no ensino de ciências que seja sensível à diversidade cultural. Isto porque, ao contribuir para que o estudante possa compreender a estrutura e o domínio de aplicação dos diferentes modos de conhecer, o ensino de ciências estará valorizando a diversidade cultural por seus próprios critérios de validade e legitimidade (EL-HANI; MORTIMER, 2007).

PE8 apresentou uma resposta que sugere a concepção de que a ciência possui um método único, e que os conhecimentos científicos são resultantes das observações e experiências sensoriais sobre o mundo natural. Como discutem Gil-Pérez et al. (2001), é preciso recusar a ideia de que a ciência trabalha com um único método, uma vez que a história da construção do conhecimento científico é marcada por um pluralismo metodológico. Outra recusa que deve ser feita, ainda de acordo com Gil-Pérez et al. (2001, p. 136), é a “[...] de um empirismo que concebe os conhecimentos como resultados da inferência indutiva a partir de dados puros". Afinal, os dados obtidos nas pesquisas científicas devem ser sempre interpretados à luz de um sistema teórico para que possam ter sentido. Os dados científicos não podem ser obtidos e nem interpretados apenas com base nas observações em experimentações. 
De fato, definir o termo ciência não é uma tarefa de fácil realização, já que inexiste um posicionamento epistemológico único entre filósofos da ciência. Tal dificuldade também foi apontada pelas professoras após as suas participações no curso de formação continuada, como podemos ver na fala de PE6. Essa professora atribuiu a ausência de um único conceito para o termo "ciência" à mutabilidade da própria atividade científica. Após sua participação no curso de formação continuada, PE6, assim como as demais entrevistadas, apresentou uma resposta satisfatória, tendo como parâmetro o conceito de ciência de Cobern e Loving (2001). A seguir, serão apresentadas as características das atividades científicas segundo algumas professoras, além de PE6: - A ciência como uma cultura que possui linguagem própria e que investiga os fenômenos naturais (PE8); - A ciência é histórica e está delimitada em campos específicos de investigação, realiza e possibilita novas descobertas (PE9).

Apesar de as professoras conseguirem uma definição satisfatória, após o curso, uma delas, PE5, demonstrou insegurança na sua fala, que parece ser por conta de que ela - ao mesmo tempo em que concorda com a ideia de que as atividades científicas são apenas sobre o mundo natural - também acede à possibilidade de abrangência do sobrenatural. Sobre esta problemática, é preciso considerar que, para definir ciência, é importante questionar a sua natureza, incluindo aí o conjunto de características que lhe são peculiares, as quais, por sua vez, são compartilhadas por cientistas de uma determinada época. Uma dessas características, concordando com Cobern e Loving (2001), é a de que as atividades científicas são apenas sobre o mundo natural.

\section{Conclusões}

A etnobiologia pode contribuir para a formação dos professores de ciências que sejam sensíveis à diversidade cultural porque apoia esses profissionais na investigação e compreensão dos conhecimentos culturais dos estudantes com relação à natureza, e, do mesmo modo, a própria prática pedagógica voltada ao diálogo entre saberes culturais. Essa afirmativa decorre de análises das entrevistas realizadas com nove professoras de biologia da rede pública de ensino do Estado da Bahia, nas quais foi possível verificar que o curso de formação continuada envolvendo a etnobiologia gerou oportunidades para que essas professoras refletissem sobre as suas práticas pedagógicas e relações com a diversidade cultural, podendo ressignificá-las, no sentido de terem em conta os conhecimentos culturais dos estudantes para a realização de diálogos com os conteúdos científicos ensinados.

Especificamente, as análises das entrevistas revelaram indícios de mudanças nas suas concepções após as suas participações no curso. Consideram-se indícios de mudanças, e não mudanças, pelas seguintes razões:

- não houve uma avaliação mais aprofundada que buscasse evidenciar a existência de coerência ou contradições no discurso e, também, entre o discurso e a prática das professoras participantes;

- as questões não foram igualmente respondidas pelas professoras antes e após o curso, já que houve desistências, não possibilitando, assim, comparações de todas as falas nesses momentos;

- pela própria complexidade da temática do curso, sendo, para algumas professoras, a primeira aproximação ao tema; 
- as respostas dadas pelas professoras foram no contexto específico do curso e, sendo assim, é possível que as professoras tenham buscado atender às expectativas da pesquiadora, sem terem se apropriado de maneira mais profunda dos significados envolvidos.

A análise das concepções apresentadas pelas professoras de biologia ao final do curso indica que a formação continuada de professores de ciências para a diversidade cultural constitui um processo lento e complexo, que não pode acontecer apenas com a participação em cursos pontuais de formação continuada. É preciso considerar questões que envolvem desde a formação inicial até a própria cultura escolar de cada professor e as políticas públicas da educação no país.

Por fim, é importante salientar a importância da realização de cursos de formação continuada de professores de ciências que trate da etnobiologia para a prática pedagógica que respeita e considera os saberes culturais dos estudantes. Do mesmo modo, é importante informar que existe a pretensão, por parte da autora, de dar continuidade à presente linha de pesquisa por meio de investigações sobre possíveis contribuições da etnobiologia para a formação inicial dos professores de ciências, bem como sobre as relações entre indícios de mudanças de concepções e mudanças de práticas pedagógicas em ciências que sejam sensíveis à diversidade cultural.

\section{Referências}

ALBUQUERQUE, U. P.; LUCENA, R. F. P. de. Métodos e técnicas na pesquisa etnobotânica. Recife: NUPEEA, 2004.

BANDEIRA, F. S. F. Construindo uma epistemologia do conhecimento tradicional: problemas e perspectivas. In: ENCONTRO BAIANO DE ETNOBIOLOGIA E ETNOECOLOGIA, 1., 2001, Feira de Santana. Anais... Feira de Santana: Universidade Estadual de Feira de Santana, 2001. p. 109-133.

\section{BAPTISTA, G. C. S. A contribuição da etnobiologia para o ensino e a aprendizagem} de ciências: estudo de caso em uma escola pública do estado da Bahia. 2007. 180 f. Dissertação (Mestrado) - Universidade Federal da Bahia: Universidade Estadual de Feira de Santana, Salvador, 2007.

BAPTISTA, G. C; EL-HANI, C. N. The contribution of ethnobiology to the construction of a dialogue between ways of knowing: a case study in a Brazilian public high school.

Science \& Education, Hoboken, v. 18, n. 3-4, p. 503-520, 2009.

BERKES, F.; FOLKE, C. Linking social and ecological systems: management practices and social mechanisms for building resilience. Cambridge: Cambridge University Press, 1998.

BERLIN, B. Ethnobiological classification: principles of categorization plants and animals in traditional societies. Princeton: Princeton University Press, 1992.

BRASIL. Ministério da Saúde. Conselho Nacional de Saúde. Normas para pesquisa envolvendo seres humanos. 2. ed. Brasília, 2003. 
CANDAU, V. M. F. Diferenças culturais, cotidiano escolar e práticas pedagógicas. Currículo sem Fronteiras, Lisboa, v. 11, n. 2, p. 240-255, 2011.

CANEN, A. Universos culturais e representações docentes: subsídios para a formação de professores para a diversidade cultural. Educação \& Sociedade, Campinas, v. 22, n. 77 , p. 207-227, 2001.

CERTEAU, M. de. As artes de fazer: a invenção do cotidiano. Petrópolis: Vozes, 1998.

COBERN, W. W. Apples and oranges: a rejoinder to Smith and Siegel. Science Education, Hoboken, v. 13, n. 6, p. 583-589, 2004.

. Constructivism and non-western science education research. International

Journal of Science Education, Abingdon, v. 4, n. 3, p. 287-302, 1996.

COBERN, W. W.; LOVING, C. C. Defining science in a multicultural world: implications for science education. Science Education, Hoboken, v. 85, n. 1, p. 50-67, 2001.

CURRIE, H. 'Minorities', 'margins', 'misfts' and 'mainstreams'. Teaching and Teacher Education, Oxford, v. 22, p. 835-837, 2006.

DELIZOICOV, D. Pesquisa em ensino de ciências como ciências humanas aplicadas.

Caderno Brasileiro de Ensino de Física, Florianópolis, v. 21, n. 2, p. 145-175, 2004.

Disponível em: < https://periodicos.ufsc.br/index.php/fisica/article/view/6430 > Acesso em: 21 maio 2015.

DELIZOICOV, D.; ANGOTTI, J. A.; PERNAMBUCO, M. M. Ensino de ciências: fundamentos e métodos. São Paulo: Cortez, 2002.

EL-HANI, C. N.; BANDEIRA, F. P. S. F. Valuing indigenous knowledge: to call it science will not help. Cultural Studies of Science Education, Dordrecht, v. 3, n. 3, p. 751-779, 2008.

EL-HANI, C. N.; MORTIMER, E. F. Multicultural education, pragmatism, and the goals of science teaching. Culture Studies of Science Education, Dordrecht, v. 2, n. 3, p. 657-702, 2007.

FELDMANN, M. G. Formação de professores e cotidiano escolar. In: . Formação de professores e escola na contemporaneidade. São Paulo: Senac São Paulo, 2009. p. 71-80.

GIL-PÉREZ, D. et al. Para uma imagem não deformada do trabalho científico. Ciência \& Educação, Bauru, v. 7, n. 2, p. 125-153, 2001. Disponível em: < http://dx.doi.org/10.1590/ S1516-73132001000200001>. Acesso em: 21 maio 2015.

HILL, D. O neoliberalismo global, a resistência e a deformação da educação. Currículo sem Fronteiras, Lisboa, v. 3, n. 2, p. 24-59, 2003.

INTERNATIONAL SOCIETY OF ETHNOBIOLOGY. Who we are. Disponível em: <http://www.ethnobiology.net/about/>. Acesso em: 04 abr. 2012. 
IRZIK, G.; NOLA, R. A family resemblance approach to the nature of science for science education. Science \& Education, Hoboken, v. 20, n. 7-8, p. 591-607, 2011.

JIMÉNEZ-ALEIXANDRE, M. P.; BUGALLO RODRÍGUEZ, A.; DUSCHL, R. A. "Doing the lesson" or "doing science": argument in high school genetics. Science Education, Hoboken, v 84, n0 6, p. 757-792, 2000.

LEDERMAN, N. G. Nature of science: past, present, and future. In: ABELL, S. K.; LEDERMAN, N. G. (Ed.). Handbook of research on science education. New Jersey: Lawrence Erlbaum, 2006. p. 831-880.

LOPES, A. R. C. Pluralismo cultural em políticas de currículo nacional. In: MOREIRA, A. F. B. (Org.) Currículo: políticas e práticas. Campinas: Papirus, 1999. p. 59-80.

MORTIMER, E. F. Linguagem e formação de conceitos no ensino de ciências. Belo Horizonte: Editora UFMG, 2000.

RODRIGUES, C.; KRÜGER, V.; SOARES, A. C. Uma hipótese curricular para a formação continuada de professores de ciências e de matemática. Ciência \& Educação, Bauru, v. 16, n. 2, p. 415-426, 2010. Disponível em: <http://dx.doi.org/10.1590/S1516$73132010000200010>$. Acesso em: 21 maio 2015.

RODRIGUES, M. I. R.; CARVALHO, A. M. P. de. Professores-pesquisadores: reflexão e mudança metodológica no ensino de física - o contexto da avaliação. Ciência \& Educação, Bauru, v. 8, n. 1, p. 39- 53, 2002. Disponível em: <http://dx.doi.org/10.1590/S151673132002000100004>. Acesso em: 21 maio 2015.

SCHÖN, D. A. Formar professores como profissionais reflexivos. In: NÓVOA, A. (Coord.). Os professores e a sua formação. Lisboa: Dom Quixote, 1992. p. 77-91.

TARDIF, M. Saberes docentes e formação profissional. Petrópolis: Vozes, 2002.

ZARAGOZA, J. M. E. O mal-estar docente: a sala de aula e a saúde dos professores. Bauru: EDUSC, 1999. 